\title{
UM ESTUDO BIBLIOMÉTRICO SOBRE A PESQUISA OPERACIONAL APLICADA À SUSTENTABILIDADE A BIBLIOMETRIC STUDY ON OPERATIONAL RESEARCH APPLIED TO SUSTAINABILITY
}

\author{
Victor Hugo Souza de Abreu ${ }^{1}$ \\ Marina Leite de Barros Baltar ${ }^{2}$ \\ Andrea Souza Santos ${ }^{3}$
}

\section{Resumo}

A sustentabilidade está sendo cada vez mais vista como uma possível solução para os problemas decorrentes, principalmente, da ação humana no meio ambiente. Entretanto, para que seus efeitos sejam observados à longo prazo faz-se necessário que sejam utilizadas abordagens como a Pesquisa Operacional (PO) que busca solucionar, ou pelo menos minimizar, problemas reais e complexos, fornecendo apoio aos tomadores de decisão. Nesse sentido, este estudo busca realizar uma revisão da literatura com abordagem bibliométrica que tem como objetivo identificar estudos que utilizam a PO aplicada à sustentabilidade. Para obter e compilar as informações, foram utilizados os bancos de dados do Web of Science ${ }^{\mathrm{TM}}$, que apresenta alcance e cobertura satisfatórios. Os resultados mostram, por exemplo, que o assunto, embora antigo, continua em expansão, sendo publicados estudos em periódicos com elevada relevância científica. Além disso, nota-se que a utilização da PO é uma importante estratégia de suporte aos tomadores de decisão brasileiros de diversas áreas do conhecimento tais como saúde pública, gerenciamento urbano e rural e engenharia para promoção da sustentabilidade.

Palavras-chave: Pesquisa Operacional. Sustentabilidade. Análise Bibliométrica.

\section{Abstract}

Sustainability is increasingly being seen as a possible solution to problems arising mainly from human action on the environment. However, for its long-term effects to be observed, it is necessary to use

Agradecimento: O presente trabalho foi realizado com apoio da Coordenação de Aperfeiçoamento de Pessoal de Nível Superior - Brasil (CAPES) - Código de Financiamento 001.

${ }^{1}$ Doutorando do Programa de Engenharia de Transportes do Instituto Alberto Luiz Coimbra de Pós-Graduação e Pesquisa de Engenharia, Universidade Federal do Rio de Janeiro, Rio de Janeiro, Rio de Janeiro, Brasil. E-mail: victor@ pet.coppe.ufrj.br

${ }^{2}$ Doutoranda do Programa de Engenharia de Transportes do Instituto Alberto Luiz Coimbra de Pós-Graduação e Pesquisa de Engenharia, Universidade Federal do Rio de Janeiro, Rio de Janeiro, Rio de Janeiro, Brasil. E-mail: mabaltar@pet.coppe.ufrj.br

3 Professora Adjunta do Programa de Engenharia de Transportes do Instituto Alberto Luiz Coimbra de Pós-Graduação e Pesquisa de Engenharia, Universidade Federal do Rio de Janeiro, Rio de Janeiro, Rio de Janeiro, Brasil. E-mail: andrea. santos@ pet.coppe.ufrj.br 
approaches such as Operational Research $(O R)$ which seeks to solve, or at least minimize, real and complex problems, providing support to decision makers. Thus, this study conducts a literature review with a bibliometric approach that aims to identify studies that use the OR applied to sustainability. To obtain and compile the data, we used Web of Science TM databases, which have satisfactory range and coverage. The results show, for example, that the despite being an old subject, it is still expanding, with studies published in journals with high scientific relevance. In addition, it is noted that the use of OR is an important strategy to support Brazilian decision makers from various areas of knowledge such as public health, urban and rural management, and engineering to promote sustainability.

Keywords: Operational Research. Sustainability. Bibliometric Analysis.

\section{INTRODUÇÃO}

A Pesquisa Operacional (PO) pode ser entendida como uma abordagem científica para o estudo de problemas reais, complexos e de execução gerencial, ou seja, busca solucionar, ou pelo menos minimizar, problemas de decisão e controle referentes à determinadas situações de complexidade e incertezas por meio da construção de modelos matemáticos e algoritmos computacionais. (IGNACZAK et al., 1980; GUNASEKARAN; IRANI, 2014).

Dessa forma, a PO tem sido utilizada com sucesso em diversas áreas de aplicação tais como engenharia, energia, meio ambiente, transporte, economia, saúde e biologia para se concentrar em problemas associados a objetivos específicos. (REYNOLD; MIDGLEY, 2002; MIDGLEY; REYNOLDS, 2004; BALTAR et al.,2020).

Embora tenha havido esforços bem-sucedidos nos domínios teóricos e práticos, relacionados à $\mathrm{PO}$, ainda existem várias questões pendentes tais como: (a) desempenho energético e ambiental; (b) planejamento energético; (c) impacto ambiental; e (d) sustentabilidade. (SAHARIDIS, 2017).

Especificamente em relação a sustentabilidade, o uso de técnicas de PO (tais como programação matemática, abordagens baseadas em simulação, teoria das filas e teoria dos jogos) tem sido estudado nas últimas décadas em virtude da necessidade de uma resposta imediata e integrada aos graves problemas ambientais, sociais e econômicos. (MIDGLEY; REYNOLDS, 2004; BRANS; KUNSCH, 2010) como esgotamento dos recursos naturais, mudanças climáticas e concorrência feroz nos mercados globais. (KUNSCH et al., 2007).

Dessa forma, a PO é importante para auxiliar no processo decisório de práticas sustentáveis, permitindo a análise matemática dos fatores envolvidos na problemática e determinando seu arranjo ideal para que a operação seja otimizada. (REYNOLD; MIDGLEY, 2002; KUNSCH et al., 2009; GUNASEKARAN; IRANI, 2014). Portanto, ela busca quantificar o objeto de estudo com a finalidade de trazer soluções mais apuradas.

Na visão da sustentabilidade, a PO pode ajudar na tomada de decisões de duas maneiras: (i) por meio das ferramentas do pensamento sistêmico, com os objetivos de fornecer informações sobre o funcionamento de sistemas vivos não lineares complexos e sociedades humanas e ajudar a tomar decisões sustentáveis; e (ii) por meio da educação e treinamento da sociedade, principalmente da população mais jovem, no que se concebe ao pensamento sistêmico para comprometer a capacidade das gerações futuras de atender às suas próprias necessidades. (KUNSCH et al., 2007).

No entanto, para que a PO favoreça a sustentabilidade torna-se necessário romper o pensamento clássico de que a PO deveria fundamentalmente responder aos problemas de logística e otimização que geralmente se concentram no aspecto econômico, principalmente por meio de modelos 
matemáticos que envolvam o custo, não sendo satisfatórios aos outros dois âmbitos da sustentabilidade (ambiental e social). (KUNSCH et al., 2009; BRANS; KUNSCH, 2010; WHITE; LEE, 2009).

A falta de atenção a esses efeitos é vista como uma deficiência substancial da concepção e tomada de decisão convencionais de políticas de desenvolvimento econômico. Visto que, devido ao fato de os objetivos dos tomadores de decisão não respeitarem o tripé do desenvolvimento sustentável, observa-se historicamente a exploração de recursos naturais e outras deteriorações ambientais que acarretam redução da qualidade do ar e de vida (KELLY, 1998). Dessa forma, o debate ambiental e social é igualmente ativo quanto à necessidade de as organizações se engajarem com práticas de sustentabilidade organizacional para apoiar estratégias competitivas e de mitigação de riscos. (HAIGH; GRIFFITHS, 2008).

Assim, surge a seguinte questão: qual é o estado atual dos estudos que utilizam a PO para a promover a sustentabilidade? Portanto, este artigo tem como objetivo realizar uma revisão da literatura a respeito de artigos científicos aplicáveis ao assunto, por meio de abordagens bibliométricas, de maneira a contribuir para discussão do tema e observar a relevância em desenvolver pesquisas unindo esses dois temas.

Este estudo tem ainda como objetivos específicos: (i) apresentar a evolução das publicações e citações ao longo dos anos; (ii) identificar os principais periódicos, autores e países que publicam estudos sobre o assunto; (iii) destacar as principais palavras-chave; e (iv) verificar as principais áreas de aplicação desses estudos. Além disso, de modo a identificar os principais estudos desenvolvidos no Brasil sobre a temática, esta pesquisa descreve os estudos brasileiros incluídas no repositório de pesquisa.

Este artigo está organizado em cinco seções: Introdução, Seção Conceitual, Procedimento Metodológico, Resultados e Conclusões. Na Seção 2, há a descrição do tópico investigado e sua relevância para a investigação científica. Na Seção 3, a metodologia da pesquisa é descrita. Na Seção 4, os principais resultados bibliométricos alcançados são relatados. Finalmente, na Seção 5, destacam-se as principais observações relacionadas ao apuramento científico.

\section{SUSTENTABILIDADE E PESQUISA OPERACIONAL}

Os diversos impactos ambientais, que vêm ocorrendo, tais como o esgotamento dos recursos naturais (água potável, petróleo bruto, madeiras, metais etc.), o aquecimento global e as mudanças climáticas, fazem com que os apelos à sustentabilidade sejam cada vez mais frequentes para que a sociedade use os recursos existentes de forma consciente e polua menos o meio ambiente. (TANG; ZHOU, 2012; GONZALEZ et al., 2018; FERREIRA, 2019).

Dessa forma, nos últimos anos, a sustentabilidade tem sido um assunto amplamente discutido entre acadêmicos e funcionários de empresas, considerando a importância de proteger o meio ambiente e qualidade de vida da população, enquanto mantém os objetivos econômicos das organizações. (KLEINDORFER et al., 2005; PIPLANI et al., 2008; WHITE; LEE, 2009; GUNASEKARAN et $a l ., 2014)$. Entretanto, as estratégias para obtenção da sustentabilidade são complexas, pois precisam envolver uma combinação de fatores baseados no equilíbrio entre os âmbitos: social, econômico e ambiental.

Esses três âmbitos se juntam para adicionar todo um contexto sustentável, que dá a qualquer projeto o potencial de reduzir impactos no meio ambiente e na vida das pessoas. Em cada um deles são levados em conta contextos específicos que devem ser considerados caso a caso. (ESPINOSA et al., 2008; VINODH; JEYA GIRUBHA, 2012; ABREU; SANTOS, 2019).

Nas últimas décadas, o conceito de sustentabilidade vem evoluindo e a literatura atual é rica em estudos conceituais, qualitativos e quantitativos, que abordam as questões da sustentabilidade. 
Assim, as partes interessadas, tais como tomadores de decisão, profissionais e gerentes de grandes empresas, estão cientes da necessidade de um novo conhecimento na busca de soluções que integrem modelos matemáticos e métodos de solução, em particular abordagens de PO. (MIDGLEY; REYNOLDS, 2004; GUNASEKARAN; IRANI, 2014; GONZALEZ et al.,2018).

Dentro deste contexto, a PO pode ser utilizada como uma importante abordagem para auxiliar no processo decisório de práticas sustentáveis, pois favorece a análise matemática dos fatores envolvidos nas questões sustentáveis. (REYNOLD; MIDGLEY, 2002; MIDGLEY; REYNOLDS, 2004; KUNSCH et al., 2009). Isso porque a PO é a aplicação de métodos científicos a problemas complexos para auxiliar no processo de decisões tais como projetar, planejar e operar sistemas em situações que requerem alocações eficientes de recursos escassos. (REYNOLD; MIDGLEY, 2002; ARENALES et al., 2007).

De acordo com Hiller \& Lierbeman (2006), a PO surgiu devido a necessidade de encontrar o melhor caminho na alocação de recursos disponíveis, a fim de mitigar a tendência de unidades de uma única organização crescerem em ilhas autônomas, já que isso traz a perda de uma visão global e objetivo únicos. Na visão da sustentabilidade, as ilhas podem ser consideradas o tripé (econômico, social e ambiental) e a PO uma abordagem para interligá-las.

Assim, abordagens como essa ajudam a promover o uso sustentável dos recursos, (GONZALEZ et al., 2018) que é essencial para atender às necessidades do presente sem comprometer a capacidade das gerações futuras de atender às suas próprias necessidades. (NAÇÕES UNIDAS, 1987). Dessa forma, a PO precisa evoluir, pois representa uma importante estratégia para moldar o futuro. (BRANS, 2004; BRANS; GALLO, 2004; BRANS; KUNSCH, 2010).

Nesse sentido, diversos estudos têm utilizado a PO para auxiliar a promoção da sustentabilidade nas mais variadas áreas do conhecimento. No entanto, a seleção de trabalhos que forneçam embasamento adequado para a realização de pesquisas científicas sobre o assunto tornou-se muito complexa, pois nem tudo o que é abordado na literatura é de igual rigor (NGAI; WAT, 2002), apenas a literatura de qualidade estimula novos estudos e fornece validação da teoria original proposta pelo estudo (BARNES, 2005). Dessa forma, este artigo busca identificá-los por meio do protocolo de revisão bem definido e descrito na Seção 3 e realizar análises bibliométricas dos estudos incluídos no repositório de pesquisa, conforme exposto na Seção 4.

\section{PROCEDIMENTO METODOLÓGICO}

O procedimento metodológico adotado neste artigo é baseado em uma abordagem bibliométrica para avaliar artigos sobre a aplicação da PO na sustentabilidade. Para Wolfram (2017), a bibliometria como metodologia iniciou-se com a finalidade de avaliar e entender o desempenho das atividades de produção científica acadêmica, utilizando para tanto uma quantidade de dados, referentes ao período pesquisado, para a extração das informações necessárias. Destaca-se ainda a utilização métodos estatísticos e matemáticos que tornam o processo avaliativo da produtividade científica mais objetivo.

Para mapear a produção científica relacionada à PO aplicada à sustentabilidade, foram analisados os artigos registrados na base de dados Web of Science. Essa base de dados foi escolhida por ter um escopo e cobertura satisfatórios. (CHEN, 2010). Nesse contexto, a abordagem bibliométrica seguiu os passos apresentados na Figura 1.Vários autores buscaram discorrer sobre temas diversos utilizando uma metodologia semelhante a proposta na atual pesquisa, tais como Zhu et al. (1999), Soares et al. (2016); Silveira et al. (2018); e Bastos \& Silva (2019). 
Figura 1 - Passos da Pesquisa.

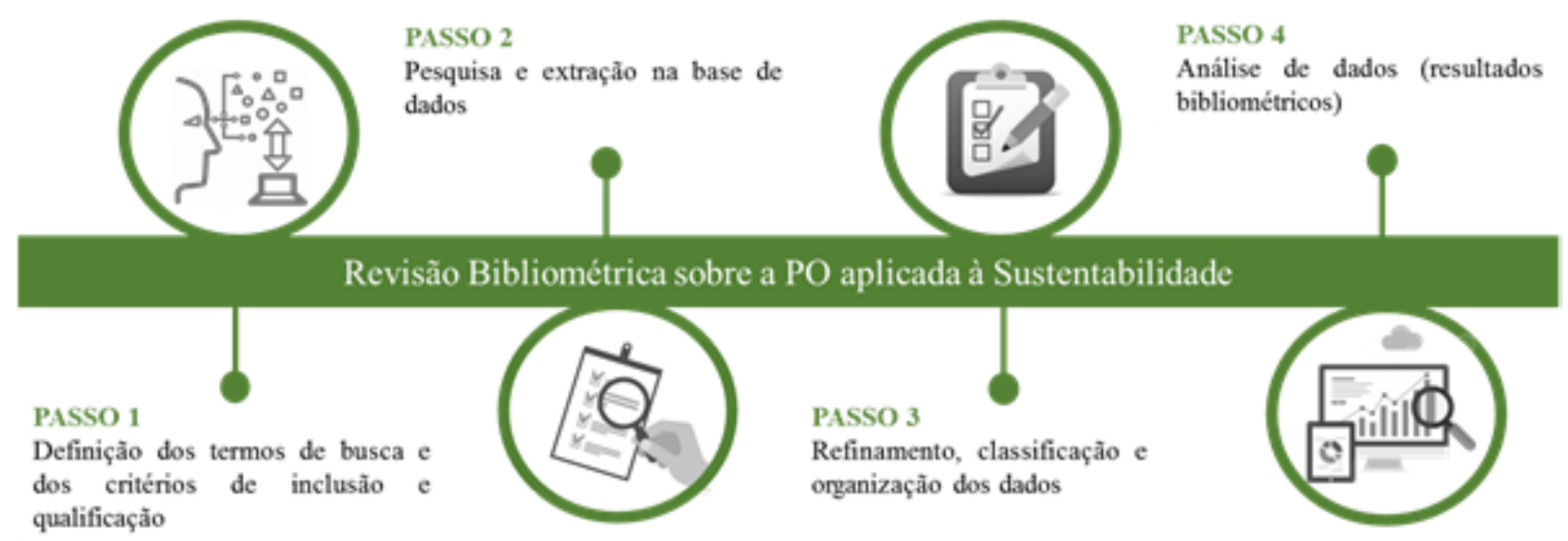

Fonte: Elaboração Própria.

No Passo 1, os termos de pesquisa mais apropriados para coleta de dados foram definidos por meio de um apuramento nas fontes primárias. A seleção destes termos pode influenciar os resultados obtidos e, portanto, é uma etapa crucial em qualquer pesquisa bibliográfica. Dessa forma, optou-se por combinar os termos em inglês 'Operational Research' e 'Sustainab*'. Cabe mencionar que a estratégia de utilizar o asterisco no final do radical do segundo termo permite que sejam encontrados tanto estudos que utilizam o termo em inglês 'Sustainability', quanto o termo em inglês 'Sustainable Development', obtendo assim um maior número de estudos condizentes com a pesquisa. Além disso, destaca-se que a utilização dos termos em inglês favorece uma maior abrangência de estudos, isso porque permitem identificar os termos de busca, tanto em artigos desenvolvidos em inglês, quanto em artigos de outras nacionalidades, como brasileiros, que apresentam resumo em inglês (ou seja, abstract).

Além disso, também foram definidos os critérios para inclusão dos artigos, necessários para a filtragem inicial, e os critérios de qualificação necessários para uma filtragem mais aprofundada. A descrição das estratégias de pesquisa é mostrada na Tabela 1.

Tabela 1 - Descrição das Estratégias de Pesquisa.

\begin{tabular}{|c|c|}
\hline Critério & Descrição \\
\hline Tópico & TS=(“Operational Research" AND “Sustainab*”) \\
\hline Base de Dados & Web of Science \\
\hline Indexes & SCI-EXPANDED, SSCI, A\&HCI, CPCI-S, CPCI-SSH, ESCI \\
\hline Inclusão & $\begin{array}{l}\text { (I) Tempo de cobertura: todos os anos do banco de dados (1945 - 2019); (II) } \\
\text { Marco com o objetivo proposto; (III) fator de impacto da revista; e (IV) tipos de } \\
\text { documentos: apenas artigos. }\end{array}$ \\
\hline Qualificação & $\begin{array}{l}\text { (I) A pesquisa apresenta uma revisão bibliográfica bem fundamentada? (II) O } \\
\text { estudo apresenta inovação técnica? (III) As contribuições são discutidas? (IV) As } \\
\text { limitações são explicitamente declaradas? e (VI) os resultados e conclusões são } \\
\text { consistentes com os objetivos pré-estabelecidos? }\end{array}$ \\
\hline Data da Pesquisa & 20 de setembro de 2019 às $09: 00 \mathrm{~h}$ \\
\hline
\end{tabular}

Fonte: Elaboração Própria. 
No Passo 2, os termos escolhidos e os filtros de inclusão foram inseridos na base de dados e os artigos encontrados por eles foram extraídos para análise posterior. No Passo 3, houve o refinamento (aplicação dos critérios de qualificação) e a classificação dos artigos selecionados. Além disso, foi realizada a organização do banco de dados. As atividades realizadas no Passo 3 são de extrema importância, pois podem identificar artigos que, embora incluídos inicialmente, não apresentam relação direta (qualidade e aplicabilidade) com o assunto estudado. No Passo 4, ocorreu a análise dos dados, conforme descrito na Seção 4.

Como limitação, menciona-se que o estudo utilizou apenas um banco de dados (Web of Science), não considerando publicações contidas em outras bases de dados como Science Direct, Scielo e Scopus. Além disso, é importante destacar que os termos de busca podem influenciar nos resultados, portanto, os artigos incluídos no repositório de pesquisa são limitados pelo banco de dados e os termos de busca utilizados.

\section{RESULTADOS}

A partir da pesquisa na base de dados e da aplicação dos critérios de inclusão e qualificação (qualidade e aplicabilidade), verifica-se que 138 publicações são elegíveis para serem incluídas no repositório de pesquisa. Nesse sentido, a descrição das investigações bibliométricas aplicadas nesse repositório encontra-se apresentada nas próximas subseções.

\subsection{Divisão por ano de publicação}

A Figura 2 mostra a evolução das publicações sobre o tema ao longo dos anos. Essa análise é importante para avaliar se a temática está defasada ou se continua em expansão, como novas oportunidades de estudos. Nela, verifica-se que a primeira publicação foi registrada em 1994 (ou seja, o assunto é antigo), mas houve constância nas publicações apenas a partir de 2004, com ápice em 2018 (ou seja, continua em expansão). Robertson (2017) afirma que a importância da sustentabilidade está aumentando ao longo dos anos devido a atual situação do planeta relacionada a crises e oportunidades. Seguindo essa lógica, nota-se que a curva representa o crescente interesse ao longo dos anos.

Figura 2 - A intensidade das publicações por ano.

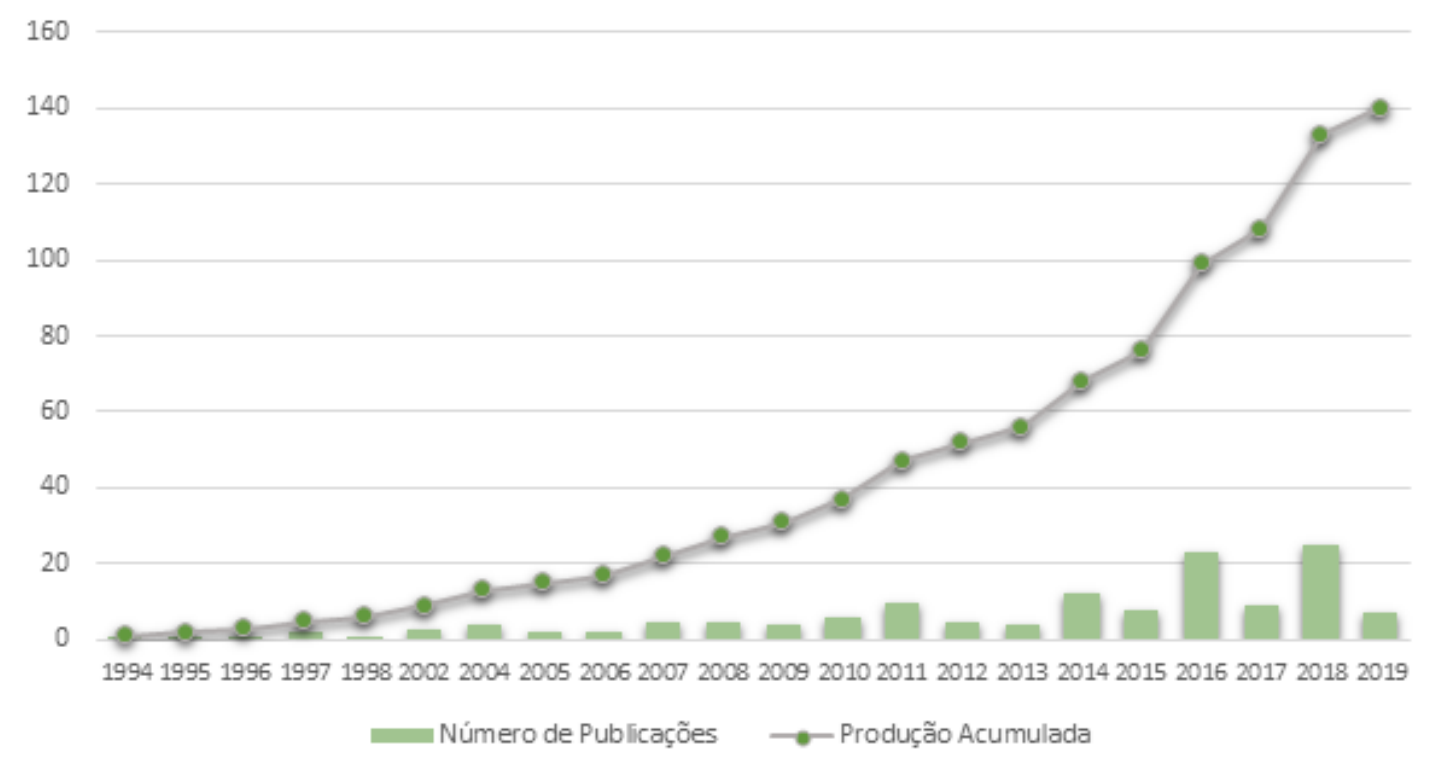

Fonte: Elaboração Própria. 


\subsection{Divisão por periódico de publicação}

Também se considera relevante avaliar os artigos incluídos no repositório por periódico de publicação, a fim de identificar quais são as revistas mais interessadas no assunto, bem como o fator de impacto de cada uma delas. Isso permite que pesquisadores direcionem seus esforços de publicação para periódicos que possuem foco direto no assunto estudado. Nesse sentido, a Tabela 2 apresenta os periódicos com volume de publicações maior que dois. Cabe mencionar que P (Publicações) refere-se ao quantitativo de artigos publicados na revista sobre a área de interesse e o FI (Fator de Impacto) avalia a importância das revistas científicas em suas respectivas áreas. Os valores apresentados na coluna IF correspondem ao ano de 2018.

Tabela 2 - A intensidade das publicações por periódico.

\begin{tabular}{|c|c|c|}
\hline Periódico & P & FI \\
\hline European Journal of Operational Research & 31 & 3.806 \\
\hline Journal of The Operational Research Society & 15 & 1.754 \\
\hline Malaria Journal & 5 & 2.798 \\
\hline BMC Health Services Research & 3 & 1.932 \\
\hline Global Health Action & 3 & 1.817 \\
\hline International Journal of Tuberculosis and Lung Disease & 3 & 2.024 \\
\hline Sustainable Development & 3 & 3.821 \\
\hline
\end{tabular}

Fonte: Elaboração Própria.

Pela Tabela 2, nota-se uma superioridade de estudos sobre a temática publicados nos seguintes periódicos: (i) European Journal of Operational Research, como31 publicações; e (ii) Journal of The Operational Research Society, com 15 publicações. Inclusive, estas duas importantes revistas científicas de PO juntas correspondem a mais de 33\% das publicações totais. Salienta-se ainda que o restante das publicações está pulverizado em outros 72 periódicos. Além disso, nota-se que, ao ordenar os periódicos por fator de impacto, é possível identificar que os mais relevantes são: Sustainable Development e European Journal of Operational Research, com fator de impacto em torno de 3.8.

\subsection{Divisão por autor}

Em relação aos principais autores, a Figura 3 apresenta aqueles cujo volume de publicação é, no mínimo, igual a dois artigos. Esta análise permite identificar autores que podem ser considerados referencias mundiais na temática sob investigação. Entretanto, pela Figura 3, nota-se que não há uma superioridade significativa de publicações por um autor em específico. $\mathrm{O}$ autor com maior número de publicações (Espinosa, A) desenvolveu seus estudos na Colômbia ligando questões ambientais com intervenções cibernéticas, (ESPINOSA; WALKER, 2005) e argumentando a importância de usar ferramentas analíticas que englobam pensamento ecológico e sistêmico, (ESPINOSA et al., 2008), por exemplo. Menciona-se que aproximadamente 623 autores estão listados nas 140 publicações do repositório da pesquisa. 
Figura 3 - A intensidade das publicações por autor.

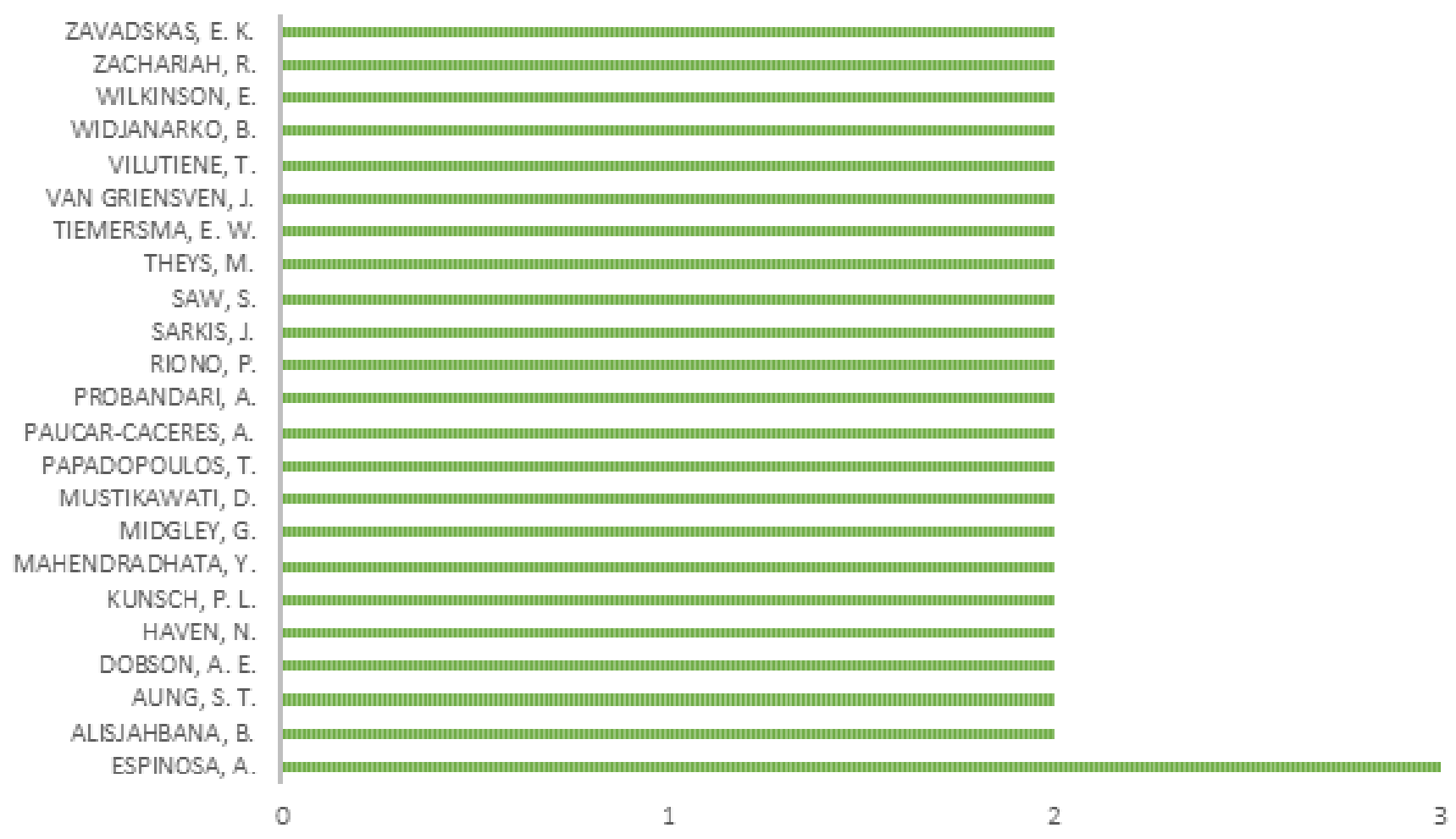

Fonte: Elaboração Própria.

\subsection{Divisão por país de publicação}

Também é pertinente avaliar os países de origem das instituições de ensino dos autores que publicam estudos sobre o assunto, conforme identificado na Figura 4, desenvolvida com auxílio da Plataforma Bing. Isso permite mostrar quais são os países que mais desenvolvem pesquisas sobre a temática investigada, bem como demonstrar carência de investimentos em outros. Na Figura 4, destaca-se que a Inglaterra lidera o ranking com 18\% dos estudos, em seguida encontram-se EUA e França, com $8 \%$ das publicações cada, Suíça, com7\% das publicações, e Alemanha, Austrália, Bélgica, Brasil, Canadá e Nova Zelândia, com 5\% das publicações cada.

Figura 4 - A intensidade das publicações por país.

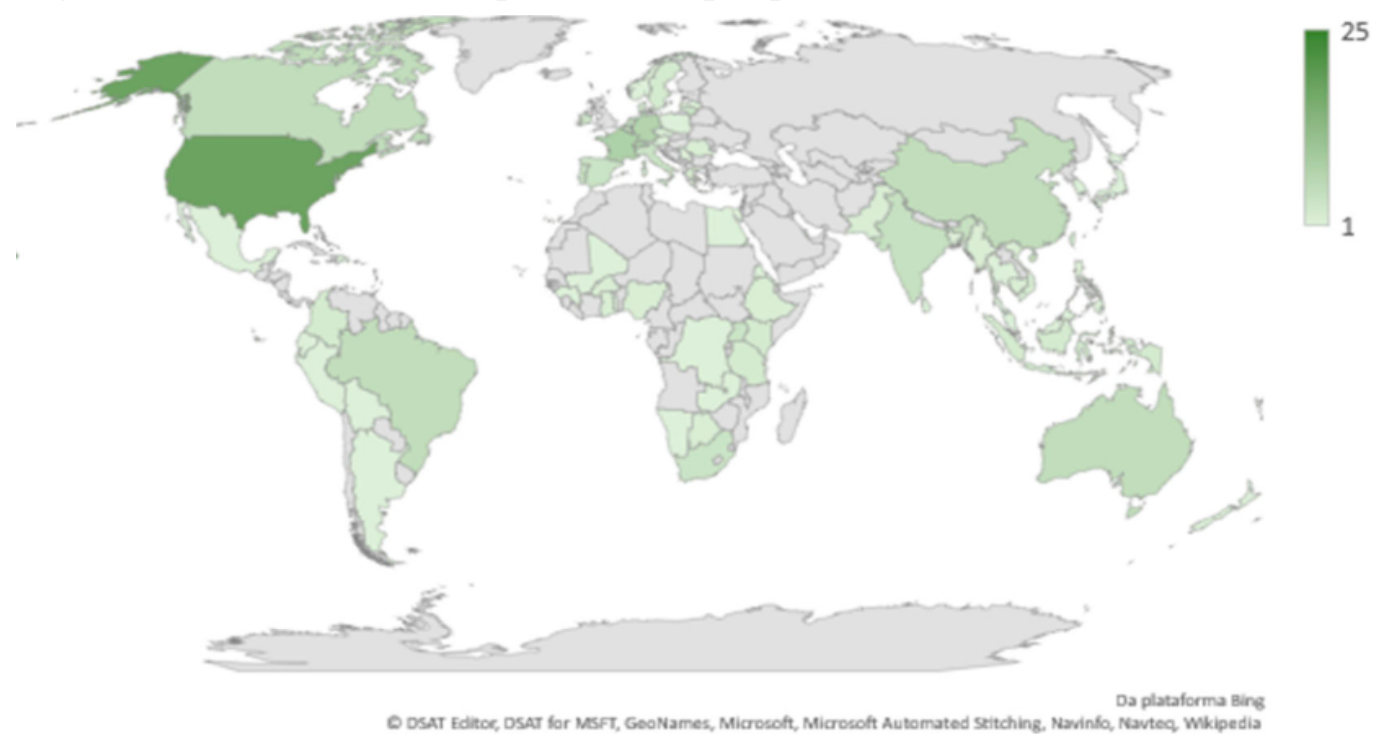

Fonte: Elaboraçào Propria. 
Dá-se ênfase ainda a expressiva participação do Brasil na temática que está na quinta posição entre os países que mais publicam estudos sobre o assunto. Dessa forma, na Subseção 4.8 são descritos os estudos brasileiros que tratam do tema, de modo a identificar como estas pesquisas utilizam a PO para promoção da sustentabilidade e seus principais resultados.

\subsection{Divisão por instituição}

Torna-se pertinente ainda avaliar quais são as instituições de ensino dos autores que publicam estudos sobre o assunto. Esses dados podem direcionar futuras parcerias entre instituições de ensino ao indicar aos pesquisadores de instituições menos expressivas quais são aquelas que mais investem em investigações sobre determinada questão sob investigação.

Nesse sentido, a Figura 5 apresenta as instituições com volume de publicações superior a dois. Nela, nota-se que as instituições que mais se destacam em publicações referentes à aplicação da pesquisa operacional na sustentabilidade são a Universidade de Londres (localizada na Inglaterra, que lidera o ranking entre os países que mais publicam estudos sobre o assunto) e a Organização Mundial da Saúde (com sede na Suíça, que $4^{\circ}$ posição do ranking), com nove publicações cada.

Figura 5 - A intensidade das publicações por instituição.

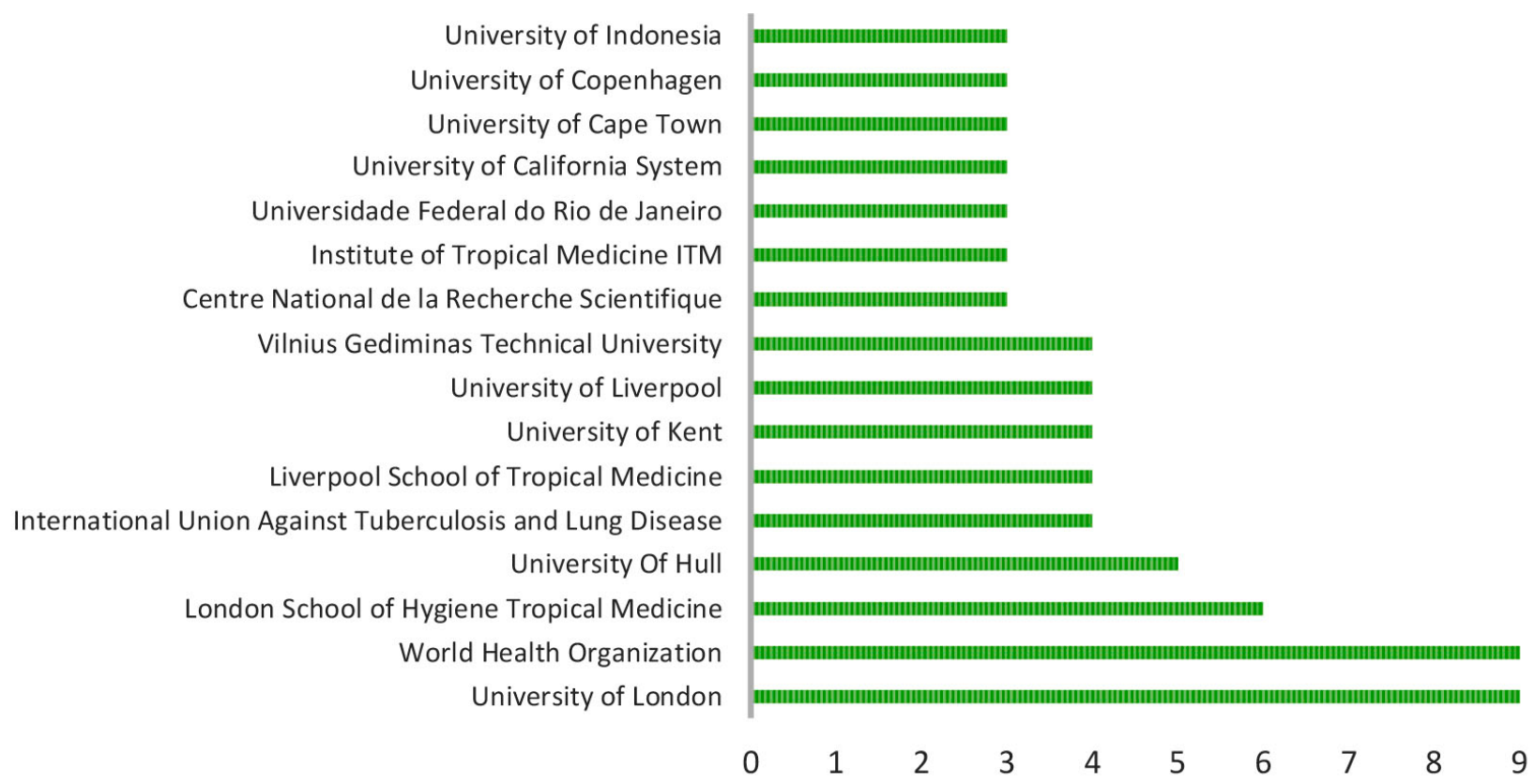

Fonte: Elaboração Própria.

\subsection{Divisão por palavra-chave}

Acredita-se também interessante avaliar as principais palavras-chave encontradas nos artigos incluídos no repositório de pesquisa, conforme identificado na rede apresentada na Figura 6, desenvolvida com auxílio do software VOSviewer. 
Figura 6-Rede de relação entre as principais palavras-chave.

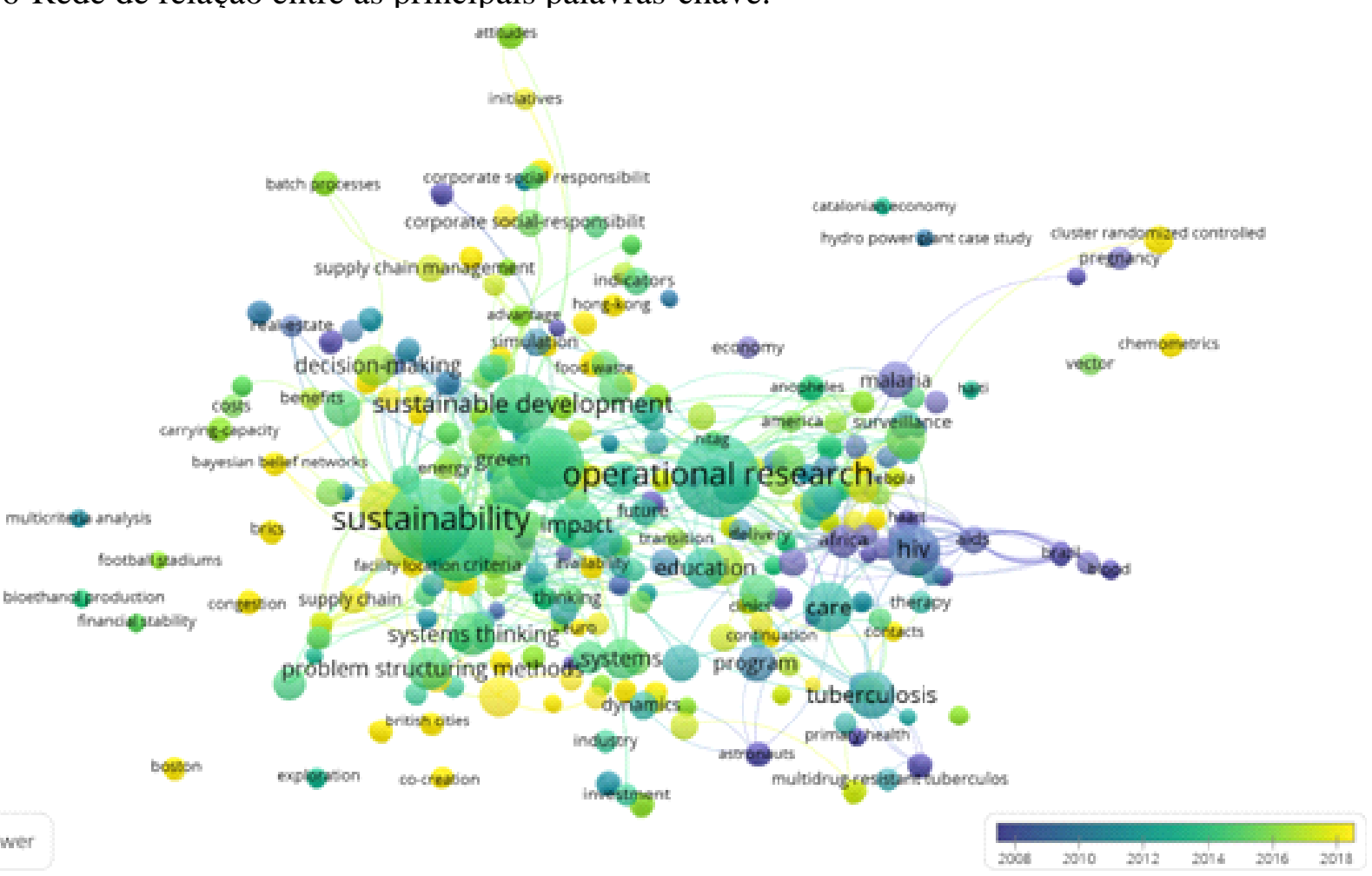

Fonte: Elaboração Própria.

A rede representada na Figura 6 é composta por 947 itens, 37 clusters e 7762 links/conexões. Nela, é possível identificar as palavras-chave mais utilizadas (de acordo com o tamanho da esfera sob sua representação), as interconexões entre elas (de acordo com as conexões entre esferas) e o período em que elas foram mais utilizadas (de acordo com a cor de cada esfera). Além disso, por meio do VOSviewer também é possível obter o mapa de calor das palavras-chave, conforme apresentado na Figura 7.

Figura 7 - Mapa de calor das principais palavras-chave.

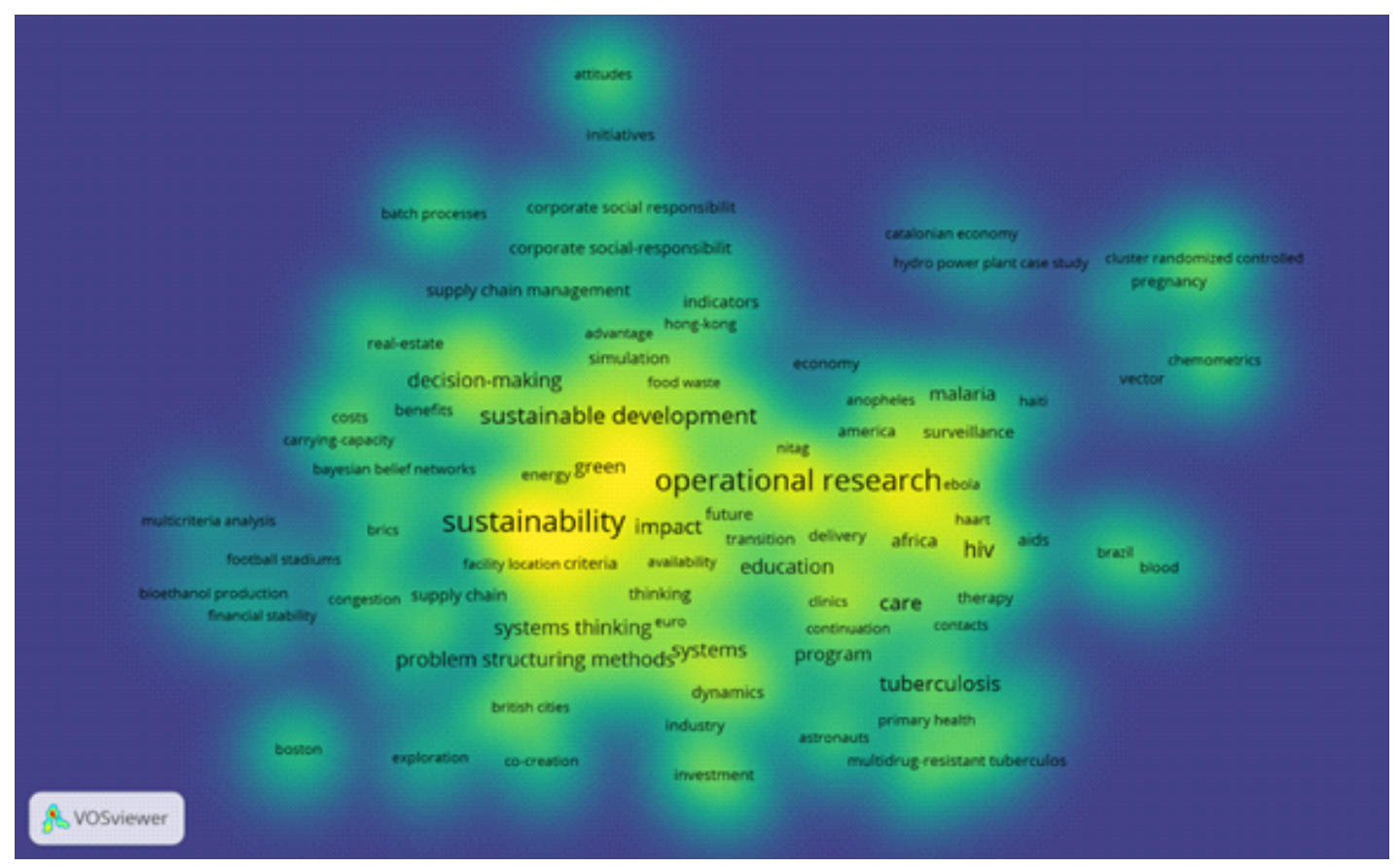

Fonte: Elaboração Própria. 
Pela Figura 7, nota-se que as palavras-chave mais recorrentes são: 'sustentabilidade' (sustainability, em inglês), 'desenvolvimento sustentável' (sustainable development, em inglês) e 'pesquisa operacional' (operational research, em inglês), como já era de se esperar devido aos objetivos da pesquisa e termos de busca definidos no Quadro 1. Entretanto, destaca-se ainda palavras-chave menos recorrentes mais de igual importância tais como 'métodos de estruturação de problemas'(problem structuring methods, em inglês), 'tomadores de decisão' (decision-making, em inglês), 'impacto' (impact, em inglês), ' energia' (energy, em inglês), 'investimento' (investiment, em inglês) entre outras.

\subsection{Divisão por área de publicação}

Em relação às temáticas que abrangem o estudo de aplicação da PO na sustentabilidade, foram evidenciadas as principais áreas de aplicação, conforme apresentadas na Figura 8.Esta análise torna-se pertinente para formar um esquema de categorização compartilhado em que é possível identificar, recuperar e analisar os documentos (artigos, capítulos de livros, etc.) relacionados a um mesmo assunto. Na Figura 8, constata-se uma superioridade de estudos que tratam sobre "Negócios e Economia", "Ciência de Gerenciamento e Pesquisa Operacional". Além disso, nota-se a presença de outras áreas importantes tais como "Saúde Pública, Ambiental e Ocupacional", "Engenharia" e "Ciências e Serviços de Saúde”.

Figura 8 - A intensidade das publicações por área de aplicação.

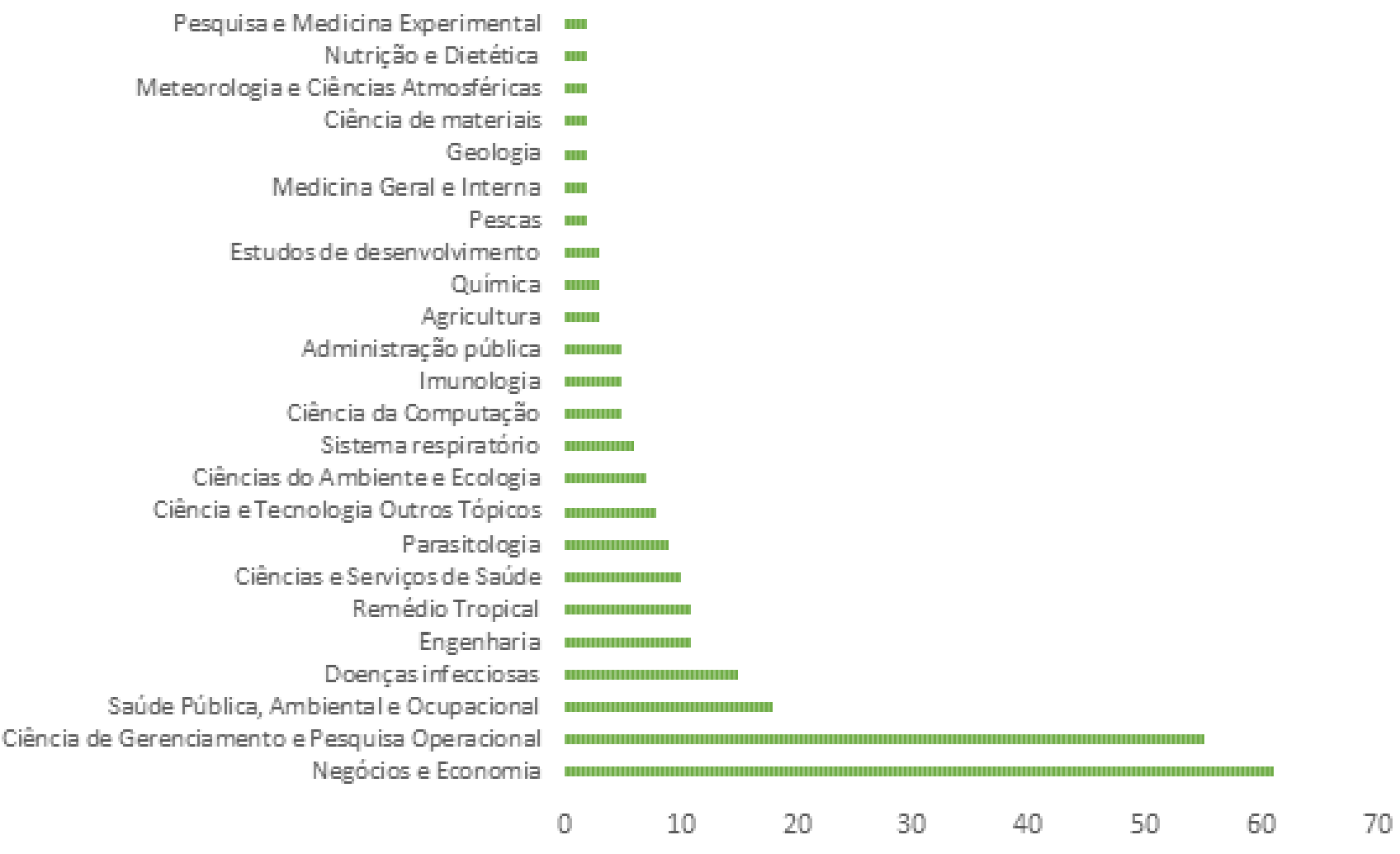

Fonte: Elaboração Própria.

\subsection{Divisão por número de citações}

Outra análise importante refere-se ao número de citações por ano, conforme apresentado na Figura 9. Essa análise, assim como a evolução das publicações ao longo dos anos, permite identificar o crescimento de interesse sobre o assunto ao longo dos anos. Nela, observa-se que a primeira citação 
ocorreu em 1997, três anos após a primeira publicação. Além disso, nota-se que o número de citações vem crescendo ao longo dos anos com ápice em 2018. Destaca-se ainda que ao todo foram identificadas 2.061citações. Esses dados demonstram, mais uma vez, que o estudo continua em expansão.

Figura 9 - A intensidade das publicações por ano de ocorrência das citações

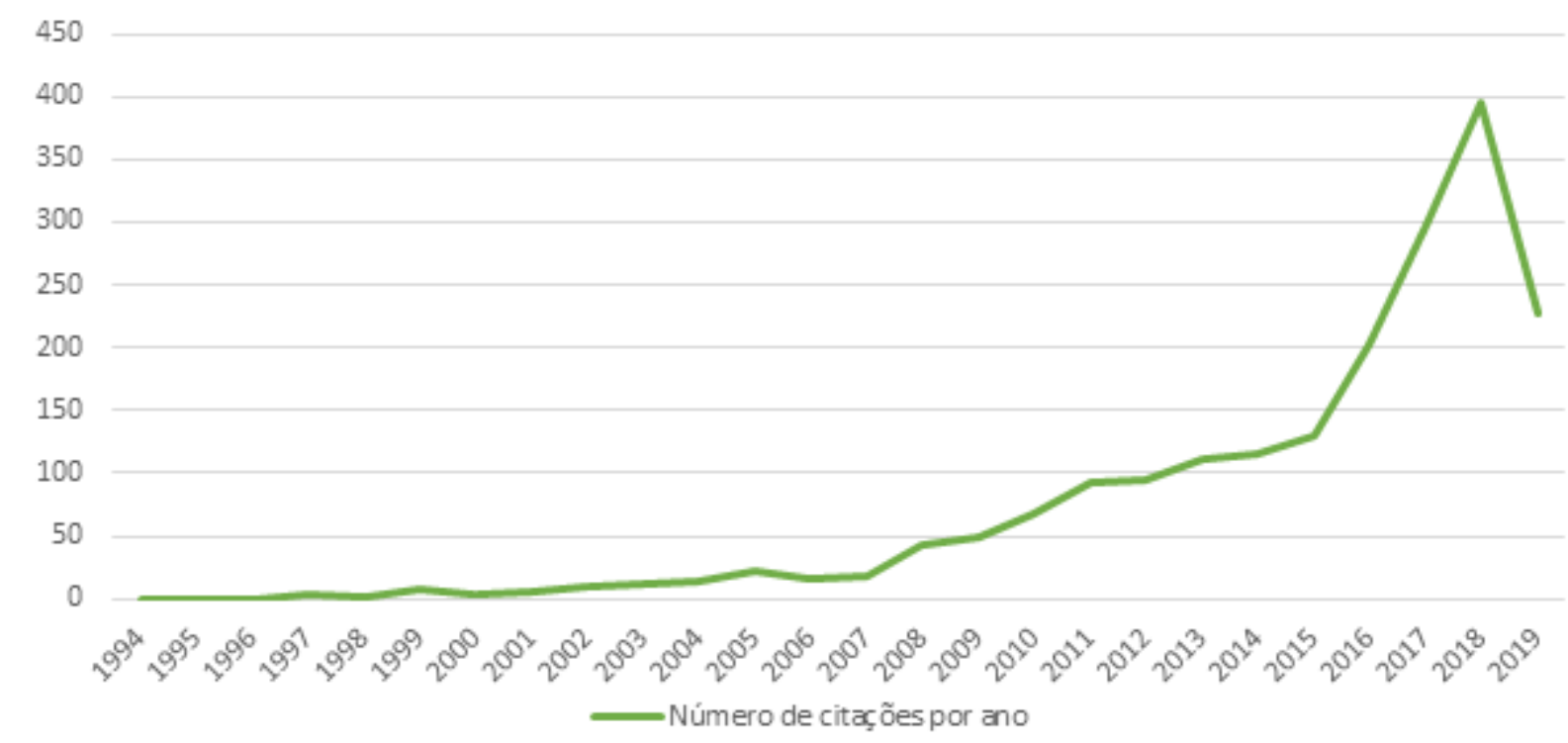

Fonte: Elaboração Própria.

Ainda sobre o número de citações é pertinente analisar como se configura a evolução das citações dos artigos mais relevantes da base de dados, conforme apresentado na Figura 10. Isso permite identificar como são distribuídas as citações de um estudo ao longo dos anos, bem como ao longo de um período de tempo em específico.

Figura 10 - A intensidade das citações por ano dos artigos mais relevantes.

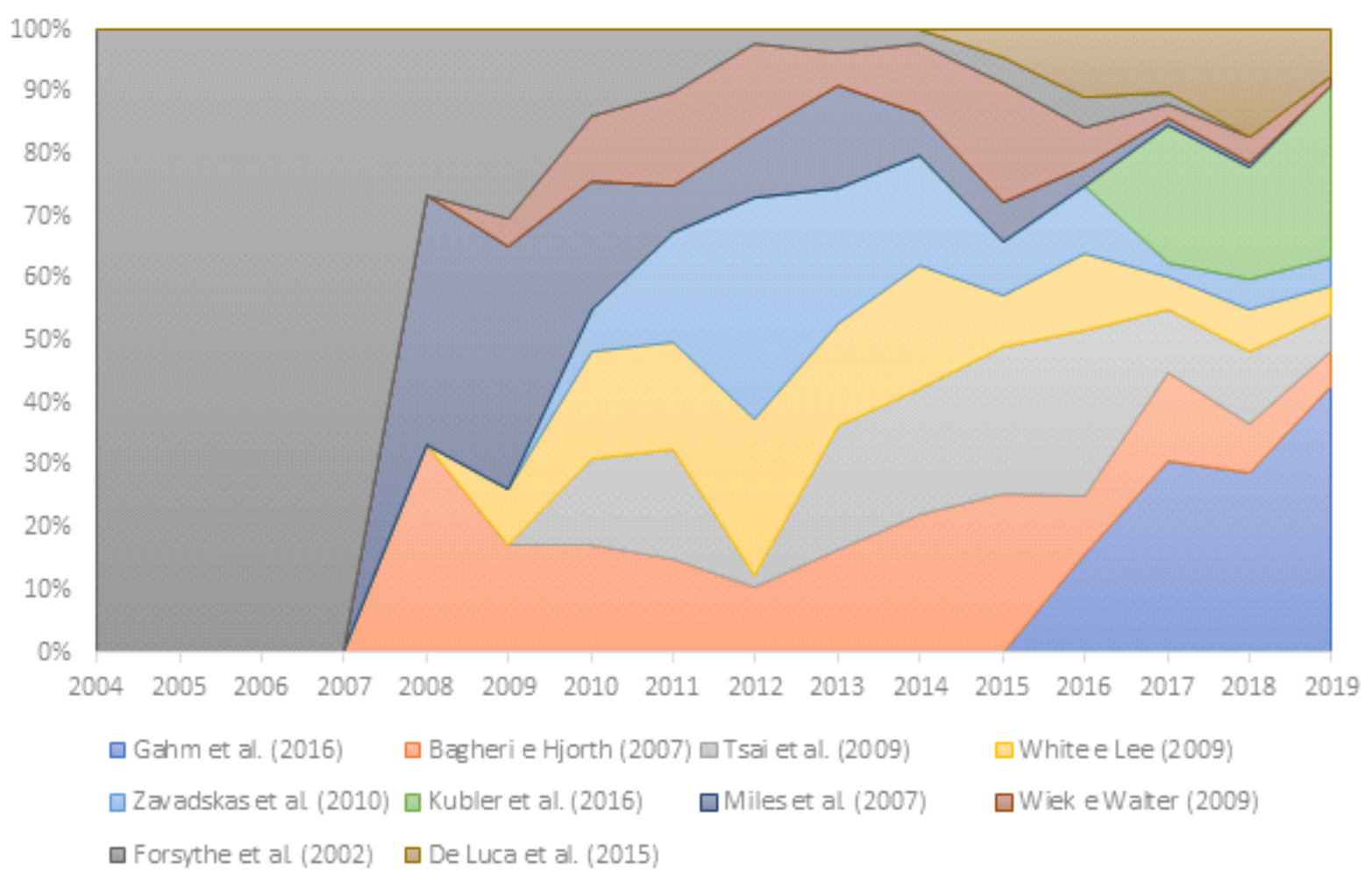

Fonte: Elaboração Própria. 
Com a Figura 10, nota-se que os 10 estudos mais relevantes da base de dados começaram a ser citados a partir de 2004 e que até o final do ano de 2009 (ou seja na década de 2000) as citações concentravam-se entre os estudos de Forsthe et al. (2002), Miles et al. (2007) e Bagheri \& Hjorth (2007). Entretanto, na década seguinte (ou seja, na década de 2010), há uma maior distribuição das citações ao longo dos anos como destaque para Bagheri \& Hjorth (2007), Tsai et al. (2009) e Gahm et al. (2016).

\subsection{Caracterização dos principais estudos brasileiros sobre o assunto}

Conforme exposto na Subseção 4.4, o Brasil apresenta expressiva participação nas publicações sobre a PO atrelada à sustentabilidade. Dessa forma, esta subseção tem como objetivo descrever os estudos brasileiros incluídos no repositório de pesquisa, conforme segue.

Quanto à área de aplicação "Ciência de Gerenciamento e Pesquisa Operacional”, os estudos brasileiros buscam identificar como deve ser realizado o gerenciamento necessário para promover a sustentabilidade por meio do uso de técnicas de PO. Veloso et al. (1994), por exemplo, descrevem um método de planejamento, que faz uso da PO, para analisar oportunidades de investimentos em regiões críticas, tais como o cerrado brasileiro. O método desenvolvido permite uma avaliação de custos e benefícios (trade-offs) entre fatores econômicos, sociais e ambientais para determinar as mais apropriadas opções de desenvolvimento local. Os esforços de modelagem permitem investigar o impacto que diferentes níveis de investimento de capital público têm sobre outras metas em um programa de desenvolvimento rural integrado. Seguindo os diferentes passos da metodologia, foi possível chegar a situações alternativas com custos e benefícios, as quais podem ser exploradas por um ou mais tomadores de decisão envolvidos em um processo de planejamento de uso dos recursos dos cerrados. Namen et al. (2009) realizam, com apoio de técnicas de PO, mais especificamente a análise de robustez, um estudo sobre a sustentabilidade na produção de alimentos, baseada no autogerenciamento, para progredir em direção à sustentabilidade de comunidades de baixa renda no Brasil. Para isso, utilizam um software chamado Robus que ajuda na aplicação da metodologia. A abordagem da análise de robustez provou ser uma maneira eficaz e aceitável de incorporar flexibilidade ao processo de desenvolvimento de comunidades de baixa renda por meio de um planejamento à longo prazo. Isso porque, para uma comunidade pobre, mudanças imprevistas ocorrem com frequência e os membros da comunidade têm pouco poder para mudar eventos que afetam diretamente seu modo de vida. Além disso, este estudo demonstrou ser um exemplo de PO comunitária na qual os modeladores trabalham, não para as hierarquias dos negócios ou do governo, mas para as organizações de base, existentes para promover os interesses de seus membros.

Quanto a área de aplicação "Saúde Pública, Ambiental e Ocupacional”, estudos brasileiros buscam identificar o papel da PO no alcance da sustentabilidade ao tratamento de doenças como HIV/AIDS e doença de Chagas. Nesse sentido, Schechter (2007) indicam que a PO deve ser parte integrante dos programas de acesso ao tratamento à epidemia de HIV/AIDS, em particular ao acesso universal à Terapia Antirretroviral (TARV), para garantir sua sustentabilidade à longo prazo. Essa abordagem está focada em maximizar a sobrevivência à doença, levando em consideração os requisitos operacionais e programáticos necessários para alcançar o acesso sustentável a um tratamento eficaz. Ramos et al. (2010) analisam o papel da PO, bem como os desafios enfrentados, para integração da assistência e do controle da doença de Chagas no Sistema Único de Saúde. Entre as questões identificadas no estudo inserem-se aspectos relativos à gestão do programa, vigilância, controle, diagnóstico, tratamento, prevenção e reabilitação e educação e comunicação. Os resultados indicam ainda que a estratégia da aplicação da PO na saúde pode, em última análise, fortalecer a vigilância 
do Sistema Único de Saúde, a partir da melhora da qualidade e da eficiência das ações de controle da doença de Chagas. Além disso, apontam que mobilização de esforços de diferentes naturezas (gestão de programas, instituições acadêmicas, trabalhadores da área da saúde, organizações não governamentais, movimento social) amplia a sua factibilidade e sustentabilidade. Por fim, Jauregui et al. (2015) verificam como a elaboração e a incorporação de modelos de PO pode fortalecer a capacidade técnica para indicar decisões baseadas em evidências sobre a introdução de novas vacinas, concentrando-se principalmente em avaliações econômicas. As evidências acumuladas sugerem que iniciativas com ênfase em treinamento sustentável e apoio direto aos países de baixa e média renda da América Latina e Caribe podem ajudar a acelerar a introdução das novas vacinas mais valiosas ao mercado. Dessa forma, redes internacionais e regionais de colaboradores são necessárias para fornecer suporte técnico e ferramental às equipes nacionais para a introdução de novas vacinas, sendo fundamental para maximizar a eficiência e o impacto dos programas de vacinação.

Quanto à área de aplicação "Engenharia", os estudos brasileiros buscam identificar estratégias precisas que podem ajudar o processo de construção sustentável a se tornar muito mais eficiente e econômico. Toffano et al. (2016), por exemplo, propõem uma metodologia para a escolha de estádios/arenas, baseada no Problema de Cobertura de Conjuntos (PCC) da PO. Essa metodologia permite selecionar aqueles estádios/arenas que apresentam o menor custo e atendem ao maior número possível de medidas que visam à sustentabilidade da construção civil. A metodologia utilizada é capaz de encontrar estádios de futebol que contemplam um maior número de ações de sustentabilidade construtivas, ao menor custo. Três diferentes tipos de capacidade de estádios foram testados de forma a verificar essa aplicabilidade. Entretanto, uma limitação constatada nessa metodologia é que a busca pelo menor preço, atendendo ao maior número possível de itens de sustentabilidade, aponta como solução ótima uma combinação entre dois ou mais estádios. Bueno \& Fabricio (2018) discutem as consequências das simplificações dos dados e da metodologia da Avaliação do Ciclo de Vida (Life Cycle Assessment - LCA, em inglês) do setor da construção civil nas principais ferramentas existentes que integram a ACV na plataforma de Modelagem da Informação da Construção (Building Information Modelling - BIM, em inglês), utilizando uma simulação em sistemas de parede, realizada em um plug-in BIM. A consistência dos resultados é comparada a uma ACV completa no software Gabi 6. Os resultados não foram consistentes, apesar dos esforços de pesquisa para equalizar o escopo dos estudos para fornecer uma comparação justa. As razões são provavelmente as simplificações e atalhos necessários para o desenvolvimento de uma ferramenta baseada em BIM mais simples a ser aplicada durante o processo de design, por qualquer projetista de construção sem conhecimento específico em LCA. No entanto, é provável que o desempenho do plug-in tenha melhorado o suficiente para permitir ao usuário obter resultados confiáveis, mais próximos aos fornecidos por um software dedicado à $\mathrm{ACV}$, para direcionar os tomadores de decisão na direção certa durante os estágios iniciais do projeto, quando não houver informações abrangentes e opções precisas disponíveis.

Assim, nota-se que a PO fornece suporte de forma mais precisa aos tomadores de decisão de diversas áreas do conhecimento, por meio de um conjunto aprimorado de abordagens de solução que integram modelos matemáticos e métodos de solução para resolver problemas diretamente alinhados à sustentabilidade, evitando também a ocorrência de erros e falhas operacionais. Isso mostra uma evolução nos processos decisórios das partes interessadas (governo, empresas, sociedade, etc.) que atualmente consideram, não apenas aspectos econômicos ou tecnológicos relacionados à geração atual, mas também vários pontos de vista relacionados ao bem-estar social e ambiental e às necessidades das gerações presentes e futuras. 


\section{CONSIDERAÇÕES FINAIS}

A eclosão da bibliometria tem contribuído para a mensuração e compreensão da evolução das produções de conhecimentos científicos, e da avaliação das atividades intelectuais de pesquisadores, com base em técnicas quantitativas e estatísticas. Além disso, possibilita, o reconhecimento dos autores e a exposição da literatura existente e relevante nas diversas áreas de pesquisa.

Dessa forma, este artigo buscou realizar um estudo bibliométrico sobre a aplicação da PO na sustentabilidade, dada a importância do assunto para solução, ou pelo menos mitigação, de problemas complexos reais decorrentes, por exemplo, dos efeitos negativos advindos da ação humana no meio ambiente tais como a ocupação desenfreada do solo, principalmente em meio urbano, exploração dos recursos naturais, aumento da poluição atmosférica, sonora e visual e desigualdade social e disseminação de doenças.

Como resultados das abordagens bibliométricas, observa-se que a produção acadêmica e o número de citações estão em uma curva ascendente, que não há predominância de estudos por um autor/grupo específico e que dois periódicos se destacam no número de publicações, que são: European Journal of Operational Research; e Journal of The Operational Research Society. Além disso, a Inglaterra lidera o ranking de publicações por país, seguida por EUA e França. Destaca-se ainda que o Brasil ocupa a $5^{\circ}$ posição do ranking.

Este estudo buscou também verificar quais são as palavras-chave mais recorrentes, por meio de uma rede de interligação e um mapa de calor, e apresentou as principais áreas de aplicação da PO na sustentabilidade. Os resultados indicam desde palavras-chave mais intuitivas tais como 'sustentabilidade' e 'pesquisa operacional' até outras, menos intuitivas, tais como 'métodos de estruturação de problemas' e 'tomadores de decisão'. Já quanto às áreas de aplicação, nota-se a superioridade das seguintes áreas: "Negócios e Economia"; e "Ciência de Gerenciamento e Pesquisa Operacional", com mais de 50 publicações cada.

Além disso, em relação especificamente a descrição de estudos brasileiros sobre o assunto, identifica-se que a utilização da PO é uma importante estratégia de suporte aos tomadores de decisão de diversas áreas do conhecimento tais como Saúde Pública, Ambiental e Ocupacional (principalmente no que se diz respeito ao combate a disseminação de doenças), Ciência de Gerenciamento e Pesquisa Operacional (principalmente no que se diz respeito ao gerenciamento urbano e rural local de regiões problemáticas) e Engenharia (principalmente no que se diz respeito a construção civil) para promoção da sustentabilidade.

Com base nesses resultados, verificou-se que o assunto investigado é profícuo de estudos e que há uma ascendência exponencial de estudos voltados para a temática. Tudo isso leva a crer que há um crescente interesse dos governos, empresas (públicas e privadas), instituições de ensino, sociedade, etc. em aprofundar o estudo acerca da utilização da PO para atender às necessidades sustentáveis atreladas ao seu campo de atuação, permitindo tomadas de decisão mais efetivas e construção de sistemas mais produtivos e evitando ocorrência de erros e falhas operacionais.

\section{REFERÊNCIAS}

ABREU, V. H. S.; SANTOS, A. S.A Dinâmica de sistemas como ferramenta de suporte ao transporte sustentável: uma revisão da literatura. In: XXXIII CONGRESSO NACIONAL DE PESQUISA EM TRANSPORTES, Balneário Camboriú, SC, ANPET, 2019. 
ARENALES, M. et al. Pesquisa Operacional para cursos de engenharia. Rio de Janeiro: Elsevier, 2007.

BAGHERI, A.; HJORTH, P. Planning for sustainable development: a paradigm shift towards a process-based approach. Sustainable Development, Baltimore, EUA, v. 15, n. 2, p. 83-96, 2007.

BALTAR, M.; ABREU, V.; RIBEIRO, G.; BAHIENSE, L. Multi-objective model for the problem of locating tows for incident servicing on expressways. TOP, Espanha, v.28, p.1-20, may 2020.

BARNES, S. J. Assessing the value of IS journals. Communications of the ACM, New York, EUA, v. 48, n. 1, p. 110-112, jan.2005.

BASTOS, L. M. G.; SILVA, E. N. Public Management and governance a partir da plataforma web of science: análise bibliométrica sobre a temática. Revista Brasileira de Administração Científica, Sergipe, v. 10, n. 3, p.1-10, jul./ago./set.2019.

BRANS, J.-P. The management of the future, ethics in OR: respect, multicriteria management, happiness. European Journal of Operational Research, v. 153, n.2, p. 466-467, 2004.

BRANS, J.-P.; GALLO, G. Ethics in OR/MS: Past, present and future. Quarterly Journal of the Belgian, French and Italian Operations Research Societies, v. 2, n. 2, p.165-178, 2004.

BRANS, J.-P.; KUNSCH, P. L. Ethics in operations research and sustainable development. International Transactions in Operational Research, v. 17, n. 4, p. 427-444, 2010.

BUENO, C.; FABRICIO, M. M. Comparative analysis between a complete LCA study and results from a BIM-LCA plug-in. Automation in Construction, Amsterdam, v. 90, p.188-200, jun.2018.

CHEN, $X$. The declining value of subscription-based abstracting and indexing services in the New Knowledge Dissemination Era. Serials Review, Raleigh, NC, v. 36, n. 2, p. 79-85, 2010.

DE LUCA, A. I.; IOFRIDA, N.; STRANO, A.; FALCONE, G.; GULISANO, G. Social life cycle assessment and participatory approaches: A methodological proposal applied to citrus farming in Southern Italy. Integrated Environmental Assessment and Management, Medford, MA, v. 11, n. 3, p. 383-396, mar. 2015.

ESPINOSA, A.; WALKER, J. Environmental management revisited: Lessons from a cybernetic intervention in Colombia. Cybernetics and Systems: an International Journal, v. 37, p. 75-92, 2005.

ESPINOSA, A.; HARNDEN, R.; WALKER, J. A complexity approach to sustainability - Stafford Beer revisited. European Journal of Operational Research, v. 187, n. 2, p. 636-651, 2008.

FERREIRA, D. H. L. Análise da Sustentabilidade de Empresas: uma Aplicação da Análise Envoltória de Dados. Revista Produção Online, Piracicaba, SP, v. 19, n. 1, p. 3-20, 2019. 
FORSYTHE, S. Assessing the cost and willingness to pay for voluntary HIV counselling and testing in Kenya. Health Policy and Planning, Estados Unidos, v. 17, n. 2, p. 187-195, jun.2002.

GAHM, C.; DENZ, F.; DIRR, M.; TUMA, A. Energy-efficient scheduling in manufacturing companies: A review and research framework. European Journal of Operational Research, v. 248, n.3, p. 744-757, 2016.

GONZALEZ, E. D. R. S.; ZHU, J.; ZANONI, S.; MACULAN, N. Trends in operational research approaches for sustainability. European Journal of Operational Research, v. 269, n.1, p.1-4, 2018.

GUNASEKARAN, A.; IRANI, Z. Sustainable Operations Management: design, modelling and analysis. Journal of the Operational Research Society, v. 65, n. 6, p. 801-805, 2014.

GUNASEKARAN, A.; IRANI, Z.; PAPADOPOULOS, T. Modelling and analysis of sustainable operations management: certain investigations for research and applications. Journal of the Operational Research Society, v. 65, n. 6, p. 806-823, 2014.

HAIGH, N.; GRIFFITHS, A. The environmental sustainability of information systems: considering the impact of operational strategies and practices. International Journal of Technology Management, v. 43, n.1/2/3, p. 48, 2008.

HILLIER, F.S.; LIEBERMAN, G. J. Introdução à pesquisa operacional. Tradução Ariovaldo Griese. 8.ed. São Paulo: Mc Graw Hill, 2006.

IGNACZAK, J. C.; OLIVEIRA, R. P.; OLIVEIRA, A.C. Um exemplo de aplicação da pesquisa operacional na agricultura. Pesquisa Agropecuária Brasileira, Brasília, DF, v. 15, n.3, p. 251-257, 1980.

JAUREGUI, B.; JANUSZ, C. B.; CLARK, A. D.; SINHA, A.; GARCIA, A. G. F.; RESCH, S.; ANDRUS, J. K. ProVac Global Initiative: a vision shaped by ten years of supporting evidencebased policy decisions. Vaccine, v. 33, p. A21-A27, may 2015.

LLY, K. L. A systems approach to identifying decisive information for sustainable development. European Journal of Operational Research, v. 109, n.2, p. 452-464, 1998.

KLEINDORFER, P. R.; SINGHAL, K.; VAN WASSENHOVE, L. N. Sustainable operations management. Production and Operations Management, v. 14, n. 4, p.482-492, 2005.

KUBLER, S.; ROBERT, J.; DERIGENT, W.; VOISIN, A.; LE TRAON, Y. A state-of the-art survey $\&$ testbed of fuzzy AHP (FAHP) applications. Expert Systems with Applications, v. 65, p. 398$422,2016$.

KUNSCH, P. L.; THEYS, M.; BRANS, J. P. The importance of systems thinking in ethical and sustainable decision-making. Central European Journal of Operations Research, v. 15, n. 3, p. 253-269, 2007. 
KUNSCH, P. L.; KAVATHATZOPOULOS, I.; RAUSCHMAYER, F. Modelling complex ethical decision problems with operations research. Omega, v. 37, n. 6, p. 1100-1108, 2009.

MIDGLEY, G.; REYNOLDS, M. Systems/operational research and sustainable development: towards a new agenda. Sustainable Development, v. 12, n. 1, p. 56-64, 2004.

MILES, K. Antiretroviral treatment roll-out in a resource-constrained setting: capitalizing on nursing resources in Botswana. Bulletin of the World Health Organization, v. 85, n. 7, p. 555560, 2007.

NAÇÕES UNIDAS. Report of the World Commission on Environment and Development. A/ RES/42/187. 96th plenary meeting, 1987.

NAMEN, A. A.; BORNSTEIN, C. T.; ROSENHEAD, J. Robustness analysis for sustainable community development. Journal of the Operational Research Society, v. 60, n. 5, p. 587-597, 2009.

NGAI, E. W. T.; WAT, F. K. T.A literature Review and Classification of Electronic Commerce Research. Information e Management, v. 39, n.5, p.415-429, 2002.

PIPLANI, R.; PUJAWAN, N.; RAY, S. Sustainable supply chain management. International Journal of Production Economics, v. 111, n. 2, p.193-194, 2008.

RAMOS, A. N.; MELO, F. R. M.; BARBOSA, J. C.; HEUKELBACH, J. O papel da pesquisa operacional e os desafios para integração da assistência e do controle da doença de chagas no Sistema Único de Saúde. Revista da Sociedade Brasileira de Medicina Tropical, São Paulo, p. 1-6, 2010.

REYNOLDS M; MIDGLEY G. Systems/Operational Research and Sustainable Development: towards a new agenda. In: THE 2002 INTERNATIONAL SUSTAINABLE DEVELOPMENT RESEARCH CONFERENCE, Conference Proceedings, University of Manchester, UK 8-9 April 2002. ERP Environment: Shipley; p. 384-390, 2002.

ROBERTSON, M. Sustainability, principles and practice. Routledge, Oxon; New York, 2017. SAHARIDIS, G. K. D. Operational research in energy and environment. Operational Research, v.17, n. 3, p. 693-696, 2017.

SCHECHTER, M. Treatment at scale in Brazil: a physician's perspective. AIDS, v. 21, p. S31-S35, 2007.

SILVEIRA, L.; SANTOS, J.; HANSEN, P. B. Coopetição e Inovação: Uma Análise Das Publicações Científicas Na Base Web Of Science. Revista Gestão \& Planejamento, Salvador, v.19, 2018.

SOARES, P. B.; CARNEIRO, T. C. J.; CALMON, J. L.; CASTRO, L. O.C. O. Análise 
bibliométrica da produção científica brasileira sobre tecnologia de construção e edificações na base de dados Web of Science. Ambiente Construido, Porto Alegre, RS, v.16, n. 1, p.175-185, 2016.

TANG, C. S.; ZHOU, S. Research advances in environmentally and socially sustainable operations. European Journal of Operational Research, v. 223, n. 3, p. 585-594, 2012.

TÓFFANO, R.; NAZARETH, V. S.; RIBEIRO, G. M.; JESUS, J. M. H. Uma Metodologia para determinação de arenas mais sustentáveis baseada no problema de cobertura de conjuntos. Revista de Gestão Ambiental e Sustentabilidade, São Paulo, v. 5, n. 2, p.49-63, 2016.

TSAI, W. H.; CHOU, W. C.; HSU, W. The sustainability balanced scorecard as a framework for selecting socially responsible investment: an effective MCDM model. Journal of the Operational Research Society, v. 60, p.1396-1410, 2009.

VELOSO, R. F.; MACGREGOR, M. J.; DENT, J. B.; THORNTON, P. K. Técnicas de modelagem de sistemas aplicadas em planejamento agrícola dos cerrados. Revista Agropecuária Brasileira, Brasília, DF, v. 29, n. 12, 1994.

VINODH, S.; JEYA GIRUBHA, R. PROMETHEE based sustainable concept selection. Applied Mathematical Modelling, v. 36, n. 11, p. 5301-5308, 2012.

WHITE, L.; LEE, G. J. Operational research and sustainable development: Tackling the social dimension. European Journal of Operational Research, v. 193, n.3, p. 683-692, 2009.

WIEK, A.; WALTER, A. I. A transdisciplinary approach for formalized integrated planning and decision-making in complex systems. European Journal of Operational Research, v. 197, n. 1, p. 360-370, 2009.

WOLFRAM, D. Bibliometrics Research in the Era of Big Data: Challenges and Opportunities. In: MUGNAINI, Rogério; ASA, Fujino; KOBASHI, Nair (orgs). Bibliometria e cientometria no Brasil: infraestrutura para avaliação da pesquisa científica na Era do Big Data. São Paulo: ECA/ USP, 2017. p. 91-101.

ZAVADSKAS, E. K.; TURSKIS, Z.; VILUTIENE, T. Multiple criteria analysis of foundation instalment alternatives by applying Additive Ratio Assessment (ARAS) method. Archives of Civil and Mechanical Engineering, v. 10, n. 3, p. 123-141, 2020.

ZHU, D.; PORTER, A.; CUNNINGHAM, S.; CARLISIE, J; NAYAK, A. A Process for Mining Science \& Technology Documents Database Illustrate for the Case of Knowledge Discovery and Data Mining. Ciência da Informação, Brasília, DF, v. 28, n.1, jan.1999. 